\title{
Thermo-physcial Properties and Characterization of TiO2 based Nanofluid Blended with Moringa Oleifera Oil
}

\section{RUBALYA VALANTINA S ( $\sim$ rvalantina@gmail.com )}

SASTRA Deemed University: Shanmugha Arts Science Technology and Research Academy https://orcid.org/0000-0002-1024-4186

Amsavahini S

SASTRA Deemed University: Shanmugha Arts Science Technology and Research Academy Janani S

SASTRA Deemed University: Shanmugha Arts Science Technology and Research Academy

Monisha G

SASTRA Deemed University: Shanmugha Arts Science Technology and Research Academy

\section{Research Article}

Keywords: Nanofluid, titanium dioxide, Moringa seed oil, viscosity, density, modelling

Posted Date: May 28th, 2021

DOl: https://doi.org/10.21203/rs.3.rs-545467/v1

License: (c) (i) This work is licensed under a Creative Commons Attribution 4.0 International License. Read Full License 


\title{
Thermo-physcial properties and characterization of $\mathrm{TiO}_{2}$ based nanofluid
} blended with Moringa oleifera oil

\author{
Rubalya Valantina $\mathrm{S}^{1^{*}}$, Amsavahini S, Janani S, Monisha G \\ ${ }^{* 1}$ Department of Physics, School of Electrical and Electronics Engineering, SASTRA \\ Deemed University, Thanjavur - 613 401, Tamilnadu, India
}

\section{Corresponding Author}

*Rubalya Valantina S,

Department of Physics, SEEE, SASTRA Deemed University, Thanjavur - 613401

Tamilnadu, India. Phone: +91 4362264107

Email: rvalantina@gmail.com

ORCHID ID: 0000-0002-1024-4186 


\begin{abstract}
:
Nanoparticle $\mathrm{TiO}_{2}$ was synthesized by the co-precipitate method and was dispersed in palm oil blended with Moringa oleifera seed oil (Enriched palm oil-EPO). Structural and compositional analysis of $\mathrm{TiO}_{2}$ nanoparticles was carried out using SEM (Scanning Electron Microscope), XRD (X-Ray Diffraction) and FTIR analysis (Fourier Transform Infrared Spectroscopy). Using the analytical method, particle dimension, crystallite size by Debye Scherrer's equation and vibrational energy of the molecule was investigated. Palm oil was blended with synthesised Moring oil to enhance its oxidative stability. $\mathrm{TiO}_{2}$ nanoparticles were dispersed at different volume fraction in EPO to analyse the temperature dependent physical properties. Bio-degradable lubricant nature of $\mathrm{TiO}_{2}$ based nanofluid was investigated by the variation of viscosity and density with temperature $\left(30\right.$ to $\left.60^{\circ} \mathrm{C}\right)$. The amphiphilic properties of fatty acids in blended oils can contribute better lubrication compared to mineral oils. Experimented viscosity and density values with temperature was fitted to a non-linear equations, and was pragmatic that quadratic equation exhibits a best fit $\mathrm{R}^{2}>0.999$. Theoretical value of the viscosity was predicted using Einstein, Batchelor, and Wang mathematical model and was compared with the experimental value. Brownian motion of the particle in the oil was studied through the diffusion constant, diffusion time, and Brownian velocity. The present study could be used to synthesis nanofluid with desired volume fraction, viscosities and densities, so as work as a suitable bio degradable lubricant in many industrial applications.
\end{abstract}

Keywords: Nanofluid; titanium dioxide, Moringa seed oil; viscosity; density; modelling 


\section{Introduction:}

Researchers, for the past two decades are working on biodegradable lubricant and coolant as nanoparticle based nanofluid are observed to be a vital substitute for petroleum based mineral oils [1]. Mineral and synthetic oils add environmental pollution to the earth. Hence, there is a need of an extensive biodegradable, non-toxic, renewable lubricants, hydraulic fluids, and coolants with high viscosity, high density, and low volatility an eco-friendly liquid $[1,2]$. Nanoparticles owe high surface to volume ratio; hence, when it is dispersed in a biodegradable and affordable vegetable oils the thermo-physical characteristics of the nanofluid properties would be enhanced [3]. Anyhow, there are some limitations in vegetable such as bad odour on oil degradation, discolouration of metal (green colour in copper), limitations in viscosity, temperature, etc. These limitations were reduced by the addition of nanoparticles as the particle plays the role of antioxidants in oil $[4,5,6]$.

The ultimate work of a nanofluid can be elucidated as a coolant- to remove the unwanted heat energy, lubricant- to reducing friction between machines, and enhancing its efficiency by safeguarding the tool life. Hence, employing inventive and eco-friendly cooling-lubricant is necessary to develop the function and life span of machines $[5,6,7]$. Moreover, as most of the worldwide lubricants are petroleum-based that produce deleterious effects on the environment by increasing pollution, toxicity, a higher cost for disposal, and non-biodegradability [7]. Mineral oils are not only biodegradable, but also they do not produce any carcinogens effect on human skin due to repeated usage also the suspended nanoparticles in vegetable oil makes it more stable to increase the heat transfer efficiency of nanofluids $[7,8]$. The average particle size has to be reduced to investigate the variation of viscosity at different volume fractions, so that nanoparticle-based nanofluid can be used to entrain into the tribocontact.

Vegetable oils, because of their durable interfaces with the machinery and lubricating surface it could be used as an anti-wear and friction modernizers. Their hydrophobic and hydrophilic composites due to the presence of long chain fatty acids, it could form a flexible film between the lubricant surfaces $[5,6,9]$. To understand their effective variability in lubricating properties, studies on variation of viscosity and density at different volume fraction are vivacious to know the agglomeration of the particles in vegetable oils. To design a bio-lubricant that can enhance the life span of the machinery parts, nanoparticles have to be dispersed in a biodegradable oil to enhance the lubricating performance even with its micro-droplets $[6,9,10]$. The dynamic Brownian motion of nanoparticles suspended in vegetable oil makes nanofluids more stable 
compared to micro-fluids, as the heat transfer efficiency of the nanofluids would become high $[10,11,12]$.

Sujith et al., (2019), in their research work, added $\mathrm{Al}_{2} \mathrm{O}_{3}$ to coconut oil and investigated the thermal, lubricating properties, and viscosity at different concentrations [13]. Xiaoming et al. 2020, for better lubrication vegetable oils, were used to spray the tool/ workpiece interface to attain an environmentally friendly turning [1]. Sina Nabati Shoghl et al, (2016) investigated the physical properties of multiwall carbon nanotubes dispersed into the water as nanofluid [14]. Şenol et al (2019), have investigated an eco-friendly lubricant at 4 different concentrations for the machining cutting conditions: surface roughness, cutting temperature, cutting force, tool wear, and tool life [7].

As viscosity and density of vegetable oils decreases with increase in temperature, it is highly used in a heat exchanger, piping, and pumping; hence, in the present work $\mathrm{TiO}_{2}$ nanoparticles was synthesized and characterized using morphological studies such as SEM (Scanning Electron Microscope), XRD (X-ray diffraction), and FTIR (Fourier Transform Infrared) spectrum. To develop a bio-lubricant, a nanoparticle of $\mathrm{TiO}_{2}$ was added to enriched palm oil (Palm oil + Moringa Oleifera seed oil) - EPO at different volume ratios, and its tribological behaviour using the parameter viscosity, and density was studied. Moringa oleifera seed oil contains 18 out of 20 amino acids and also contains antioxidants like flavonoids, polyphenols, stigmasterol, sitosterol, $\alpha, \beta, \gamma$ and $\delta$ tocopherols, and ascorbic acid [15].To improve the oxidative stability in palm oil (PO), Moringa oleifera seed oil (MO) which has high antioxidant potential was added. A $150 \mathrm{ml}$ of $\mathrm{PO}$ is blended to $4 \mathrm{ml}$ of $\mathrm{MO}$ and $\mathrm{TiO}_{2}$ at different volumes were added and a homogeneous nanofluid was synthesized using an ultrasonicator. Four samples: base fluid, and 3 samples of nanofluids were prepared with different volume fractions and their viscosity, and density were investigated at different temperatures. Prediction of viscosity and density of the desired sample could be done by the fitted mathematical model. The measured viscosity was also fitted to a theoretical model equation and compared with Einstein, Batchlor, and Wang's equations.

\section{Materials and Methods:}

Titanium nitride, hydroperoxide, hydrochloric acid, ammonia, and other chemicals were purchased in Sigma Aldrich. Moringa oleifera seeds were bought from Periyakulam, Tamilnadu, India, and the oil was prepared using hexane extract [15]. Palm oil was purchased from a government store, Thanjavur, Tamilnadu, India. 


\subsection{Preparation of $\mathrm{TiO}_{2}$ nanoparticles:}

$\mathrm{TiO}_{2}$ nanoparticles was synthesized using a chemical co-precipitate method as shown in the flowchart of figure 1. Since previous researches have studied the antimicrobial and antifungal activities of $\mathrm{TiO}_{2}[16]$, usage of the nanoparticles in nanofluid can exhibit the behaviour as an enhanced lubricant.

\subsection{Preparation of base fluid EP:}

Palm oil constitutes $50-60 \%$ of saturated fatty acids. The unsaturated fatty acids $36-47 \%$ are prone to oxidation and produce unwanted degraded products. To increase the oxidative stability of the oil, Moringa oleifera seed extract which has high potent antioxidants (rare combination of zeatin, quercetin, $\beta$-sitosterol, sigma sitosterol, enriched tocopherol, caffeoylquinic acid, and kaempferol) [15] was added to palm oil (EPO) to form $154 \mathrm{ml}$ (PO 150+ MO 4ml)

\subsection{Preparation of nanofluid:}

Nanoparticles were added with base liquids at different volume ratios and dispersed using a sonicator continuously. To create a long-time durable nanofluid, the nanoparticles were dispersed in EPO at different volume ratios $(\mathrm{S} 2-\varphi=0.2, \mathrm{~S} 3-\varphi=0.4, \& \mathrm{~S} 4-\varphi=0.6)$. After that, for 3 hours a magnetic stirrer was operated on it. Then, the prepared suspension was controlled to a 1-hour ultrasonic processor $(20 \mathrm{kHz}, 400 \mathrm{~W})$ to cut down the likely clump of nanoparticles and produce a nanofluid with excellent diffusion. No surfactants was added as it may induce chemical contamination. Sample base fluid is taken as S1, which is a mixture of $\mathrm{PO}(150 \mathrm{ml})+\mathrm{MO}(4 \mathrm{ml}) . \mathrm{S} 2$ is a nanofluid in which $\mathrm{TiO}_{2}$ is dispersed in the base fluid with the $\varphi=0.2, \mathrm{~S} 3-\varphi=0.4, \& \mathrm{~S} 4-\varphi=0.6$.

\subsection{Measurement}

Tribology nature of the nanofluid at different volume ratios along with the base fluid was determined using (1) density with ASTM standard method D891-09, (2) Viscosity with ASTM 445 was investigated precisely [4].

\subsection{Morphological studies:}

The synthesised nanoparticle was characterised using a scanning electron microscope (SEM), the nano-dimension of the particles ranges between 61 to $90 \mathrm{~nm}$. Figure 2 illustrates the study using SEM, where (a) illustrates the magnification of $10 \mu \mathrm{m}$, and (b) illustrates the magnification to $500 \mathrm{~nm}$. Figure 3 illustrates the aggregation of $\mathrm{TiO}_{2}$ in $163 \mathrm{~nm}$ with a standard 
deviation of particle size $28 \mathrm{~nm}$. The titanium dioxide $\left(\mathrm{TiO}_{2}\right)$ nanoparticles, synthesized by the co-precipitate method were subjected to the XRD method (PANalytical-PW 340/60 X'pert PRO X-ray diffractometer) for the structural confirmations [5]. Figure 4 shows the crystal structure and arrangement of the atoms that were studied using X-Ray Diffraction analysis. Using the software CMPR, the maximum intensities of dominant peaks were found and they were compared with the previous pattern. On observing both the patterns of $2 \theta$ value, there was a slight variation in the position of diffracting peaks. The experimental XRD pattern agrees with the Joint committee on powder_diffraction standards) card number JCPDS card no 211272 and the XRD pattern of $\mathrm{TiO}_{2}$ nanoparticles from other literature. From the obtained pattern, as given in table 1 , it can be noticed that the peak $(2 \theta)$ is located at $25.24^{\circ}, 37.73^{\circ}$, $48.00^{\circ}, 54.98^{\circ}$, and 62.62 . The peaks with their (h k l) values are $\left(\begin{array}{lll}1 & 0 & 1\end{array}\right),\left(\begin{array}{lll}0 & 0 & 4\end{array}\right),\left(\begin{array}{lll}2 & 0 & 0\end{array}\right),\left(\begin{array}{ll}1 & 0\end{array}\right.$ 5) and (2 04 ) for $\mathrm{TiO}_{2}$ nanoparticles. For Tetragonal structure, $\left(\alpha=\beta=\gamma=90^{\circ}\right)$. The unit cell parameters of the crystal structure were found to be $a=3.780, b=3.780, c=9.510$. Lorentz factor and Lorentz polarisation factor was determined using Clark equation and was experiential that the Lorentz factor decreases with increase in the Bragg's angle to indicate the intensity drop of the radiation reflected related to those in the forward or backward directions [5]. The result shows that maximum peaks are well indexed to the sample and it confirms that the sample is titanium dioxide.

Figure 5 shows the FTIR spectra for $\mathrm{TiO}_{2}$ nanoparticles to confirm the various functional groups present in the particles. It was observed that for various absorption frequencies the bonds of vibration changes. The FTIR spectra of $\mathrm{TiO}_{2}$ nanoparticles ranges from $400-4000 \mathrm{~cm}^{-1}$. The strong band between $3428 \mathrm{~cm}^{-1}$ could be due to the $\mathrm{O}-\mathrm{H}$ stretching of any water molecules in the nanoparticle. The peak at $1646.02 \mathrm{~cm}^{-1}$ of the spectra indicates that the stretching and bending vibrations of $\mathrm{Ti}-\mathrm{O}-\mathrm{Ti}$ bonds, also, the broad band between 800 to $400 \mathrm{~cm}^{-1}$ was related to the vibrations of tin oxide The strong band at $523.92 \mathrm{~cm}^{-1}$ was due to a metal oxygen $(\mathrm{Ti}-\mathrm{O})$ bond stretching vibrations [16].

\subsection{Viscosity and density Measurement:}

Figure 6 illustrates the variation of viscosities of base fluid, and nanofluids $(\varphi=0.2-0.6)$, with temperature from $30^{\circ}$ to $60^{\circ} \mathrm{C}$ and was experimental that the viscosity decreases with increase in temperature. The viscosity of S2 increased by $0.03 \%, \mathrm{~S} 3$ by $0.08 \%$, and $\mathrm{S} 4$ by $0.12 \%$ from the base fluid (S1). Hence, it was observed that variation of viscosity varies with temperature and volume fraction of nanoparticles. This investigation of viscosity related to volume fraction 
and its prediction is very important for any desired application in the industry. Viscosity of the vegetable oil is modified by the addition of nanoparticles to withstand high pressure and enhance the anti-friction properties in machinery $[9,16,17]$. Due to the vivacious properties such as antifungal and antimicrobial properties of $\mathrm{TiO}_{2}$, it precludes the fungal activities formed in nanofluid on hydrolysis [14]. An increase in temperatures upsurges the kinetic energy of the molecules and decreases the intermolecular interactions. Hence, the viscosity of the fluid decreases. Many researchers have investigated the modifiers of viscosity of nanofluid augments the lubricating properties as a steady tribological layer [18, 19, 20, 21]. Sujith et al, (2019) have also studied the variation of viscosity of $\mathrm{Al}_{2} \mathrm{O}_{3}+$ coconut oil-based nanofluid from $303 \mathrm{~K}$ to $343 \mathrm{~K}[13]$.

The non-linear variation of viscosities of the samples from S1 to S4 with temperature is fitted into mathematical modelling equations such as [6]:

Exponential equation: $\eta=A e^{B / T}$

Logarithmic linear equation: $\ln \eta=\mathrm{A}+\mathrm{B}^{*} \mathrm{~T}$

Logarithmic quadratic equation: $\ln \eta=\mathrm{A}+\mathrm{B} * \mathrm{~T}+\mathrm{C} * \mathrm{~T}^{2}$

Logarithmic non-linear equation: $\ln \eta=\mathrm{A}+\mathrm{B} / \mathrm{T}+\mathrm{C} / \mathrm{T}^{2}$

Table 2 illustrates the fitting of the variation of viscosity with temperatures of sample S1, S2, S3, and S4. The analysis of non-linear fittings exhibits the logarithmic quadratic equation as a best fit for all samples with good correlation $\mathrm{R}^{2}$ value for all the samples.

Theoretical equations for the determination of viscosity for the interfacial nanofluid in which nanoparticles are dispersed in liquid was predicted by Einstein, Batchelor, and Wang models $[9,16,21,22]$. Einstein model: $\eta_{n f}=\eta_{b f}(1+2.5 \varphi)$

Where volume fraction $\varphi=\frac{V_{p}}{V_{p}+V_{b}}$

$\mathrm{V}_{\mathrm{p}}$---------------------- Volume of the particle

$\mathrm{V}_{\mathrm{b}}$-------------------- Volume of the base fluid

Batchelor model: Theoretical model given by Batchelor to predict viscosity of the nanofluid is given by $[9,16]: \eta_{n f}=\eta_{b f}\left(1+2.5 \varphi+6.5 \varphi^{2}\right)$

Theoretical equation of Wang and co-researchers was a modified form of Bachelor's model as given as $[9,16]: \eta_{n f}=\eta_{b f}\left(1+7.3 \varphi+123 \varphi^{2}\right)$

To determine the theoretical values of the nanofluid at different volume fraction, Table 3 illustrates the calculated values of the viscosity using the above three models. The table 
exemplify that Einstein and Batchelor models are with good covenant compared to Wang model. Praveen et al (2007) correlated viscosity and volume fraction with Einstein, Bicerano, and Brinkman equations for a $\mathrm{CuO}$ nanoparticles dispersed in the mixture of glycol and water [22]. Similar work was done by Nabeel and Hemalatha (2013) for a nanofluid ZnO dispersed in coconut oil [10]. Amin and Farzad (2019), have studied the viscosities of $\mathrm{ZnO}$ and $\mathrm{MgO}$ in oil predicted the viscosities using above models. But the prediction of viscosities between 30 to $60^{\circ} \mathrm{C}$ was carried out in this present work [17].

Vicissitudes of experimental viscosity, enhancement viscosity, diffusion constant, and diffusion time of $\mathrm{TiO}_{2}$ based nanofluid in palm and moringa oil blend is illustrated in table 4 . Kinematic viscosity of the nanofluid was observed using laminar flow technique of the liquid and found to decrease with increasing temperature as the interactive forces get reduced in thermal agitation. Enhancement of viscosity $\left(\mathrm{EV}_{\mathrm{V}}\right)$ of a specific value for the desired application is possible with the volume fraction and size and shape of the particle $[10,22]$. The enhancement of viscosity $\left(E_{V}\right)$ of the fluid was observed to vary from 2.56 to 13.6 times the viscosity of the base fluid as illustrated in table 4 . Enhancement viscosity of the nanofluid could be calculated using the equation:

$$
E_{V}=\frac{\eta_{n f}-\eta_{b f}}{\eta_{b f}} \times 100
$$

Using Pycnometer, density of the base and nanofluids were studied at different temperature by keeping inside a water bath. Figure 7, shows the non- linear variation of densities of nanofluid with temperature. To calculate dynamic viscosity of the fluids the observed kinematic viscosity is multiplied with the density of the fluid [22, 23, 24].

Brownian motion of the particle in nanofluid could be determined using density of base fluid $\left(\rho_{b f}\right)$, nanofluid $\left(\rho_{n f}\right)$, and respective dynamic viscosity (Keblinski et al, 2002; Rubalya et al, 2018) $[12,23]$. Agglomeration or dispersion of particle in the nanofluid, particle-particle interaction, and particle- liquid interface study could be determined using Stokes- Einstein's equation: $D=\frac{k_{B} T}{3 \pi \eta d}$

D- diffusion constant, $k_{B}$ - Boltzmann constant, T- Temperature, $\eta$ - viscosity of fluid, and ddiameter of the particle. Table 4 illustrates the diffusion constant increases with temperature but decreases with volume fraction. It was experimental that the value of $\mathrm{D}$ increases with increase in temperature as given in equation (10) it is directly proportional to the temperature. D increases for (i) $\varphi=0.2$ by $66.4 \%$ (ii) $\varphi=0.4$ by $66.77 \%$, and (iii) $\varphi=0.6$ by $67.5 \%$ 
from $303 \mathrm{~K}$ to $333 \mathrm{~K}$ increase in temperature. However the value of $\mathrm{D}$ decreases with increase in volume fraction due to upsurge in viscosity that increases with the volume fraction $(\varphi)$. The value of $\mathrm{D}$ decreases by $6.2 \%$ for $\varphi=0.2$ to 0.4 , and by $11 \%$ for $\varphi=0.2$ to 0.6 at $303 \mathrm{~K}$.

To determine Brownian velocity $\left(\mathrm{V}_{\mathrm{B}}\right)$ of the particle, the diffusion time $\tau_{D}$ related to temperature could be calculated using equation [10]:

$\tau_{D}=\frac{3 \pi \eta d^{3}}{6 k_{B} T} \operatorname{in} \mu s$

Table 4 illustrates the variant of diffusion time $\tau_{D}$ with temperature and volume fraction. It was experiential that $\tau_{D}$ decreases for (i) $\varphi=0.2$ by $66.5 \%$ (ii) $\varphi=0.4$ by $66.76 \%$, and (iii) $\varphi=$ 0.6 by $67.5 \%$ from $303 \mathrm{~K}$ to $333 \mathrm{~K}$ increase in temperature.

Brownian velocity $\left(\mathrm{V}_{\mathrm{B}}\right)$ could be determined using $\mathrm{d}$ by $\tau_{D}$ as given below:

$V_{B}=\frac{2 k_{B} T}{\pi \eta d^{2}}$

The velocity $\mathrm{V}_{\mathrm{B}}$ increases with increase in temperature as it is directly proportional to the temperature. It was experiential that $\mathrm{V}_{\mathrm{B}}$ increases for (i) $\varphi=0.2$ by $66.4 \%$ (ii) $\varphi=0.4$ by $66.8 \%$, and (iii) $\varphi=0.6$ by $67.5 \%$ from $303 \mathrm{~K}$ to $333 \mathrm{~K}$ increase in temperature. The value of $\mathrm{V}_{\mathrm{B}}$ decreases by $5.8 \%$ for $\varphi=0.2$ to 0.4 , and by $11 \%$ for $\varphi=0.2$ to 0.6 at $303 \mathrm{~K}$.

All the above parameter $\left(\mathrm{D}, \tau_{D}\right.$, and $\left.\mathrm{V}_{\mathrm{B}}\right)$ were related with each other as it depends on the motion of the particle in the liquid and could be calculated between the experiential temperatures. It was observed the $\%$ of increase or decrease were almost same as it is related with the same factor, temperature and viscosity.

Table 5 illustrates the fitting of variation of density with temperature in same non-linear empirical equations (used to predict viscosity) and observed that again the second order quadratic logarithmic equation was highly correlated with good $\mathrm{R}^{2}>0.999$ value. This equation could be used to predict density of nanofluid in the experiential volume fraction and temperature.

\section{Conclusion:}

Nanosized $\mathrm{TiO}_{2}$ was synthesised by means of chemical co-precipitate method, and nanofluid was prepared by dispersing the particle in the modified palm oil. Viscosity and density of the nanofluids at different volume fraction and temperature were determined. 
Viscosity of the fluid decreases with increase in temperature and the data was fitted in empirical equations for the validity. Theoretical model equations were studied to predict viscosity at different volume fraction to extend the application of the present work. The experiential data was used to predict density at different temperature and viscosity was experimented and the data was fitted in empirical equations for statistical analysis. Brownian motion of particle in liquid was determined using diffusion constant, diffusion time, and diffusion velocity that infers the lubricating and heat transfer efficiency of the liquid.

4. Acknowledgments The authors gratefully acknowledge Vice Chancellor of SASTRA Deemed University, for the constant encouragement to carry out the research work in the University Laboratory. We also thank Pondicherry University for helping us to measure the electrical properties at different frequencies and temperatures.

5. Conflict of Interest: The manuscript is our own original work, and does not duplicate any other previously published work, including our own previously published work. The Research work is not funded by any agency. The authors and co-authors have no conflict of interest and agreed for submission to the journal.

\section{Funding}

This research did not receive any specific grant from funding agencies in public, commercial, or not-for-profit sectors.

\section{References}

[1].Xiaoming Wang, Changhe Li, Yanbin Zhang, Wenfeng Ding, MinYang, TengGao, HuajunCao, XuefengXu, DazhongWang, Zafar Said, Sujan Debnath, Muhammad Jamil, Hafiz Muhammad Ali, Vegetable oil-based nanofluid minimum quantity lubrication turning: Academic review and perspectives, Journal of Manufacturing Processes 59 (2020) 76-97 https://doi.org/10.1016/i.jmapro.2020.09.044

[2]. Marinalva Ferreira Trajano, Edja Iandeyara Freitas Moura,Kandice Suane Barros Ribeiro, Salete Martins Alves, Study of Oxide Nanoparticles as Additives for Vegetable Lubricants, Materials Research. 17(5) (2014) 1124-1128

\section{http://dx.doi.org/10.1590/1516-1439.228213}

[3]. Y. Bertrand, Development of a low viscosity insulating fluid based on vegetable oil, in: IEEE Int. Symp. Electr. Insul., IEEE (2012) 413-418. doi:10.1109/ELINSL.2012.6251501.

[4]. S. Rubalya Valantina, D. Susan, S. Bavasri, V. Priyadarshini, R. Ramya Saraswathi, M. Suriya, (2016) Experimental investigation of electro-rheological properties of modeled vegetable oils, J. of food sci. and tech. 53: 1328-1337. DOI 10.1007/s13197-015-2050-6

[5]. Sriram Subramanian, Phebee Angeline Devadasan Racheal, Rubalya Valantina 
Sathianathan, Aparna Rajagopal, Structural and Dielectric Properties of Groundnut Oil, Mustard Oil and ZnO Nanofluid, Iran J Sci Technol Trans Sci, 43 (2019), 1351-1359 https://doi.org/10.1007/s40995-018-0631-8

[6].S. Rubalya Valantina, D.R Phebee Angeline, S. Uma, B.G Jeya Prakash, Estimation of dielectric constant of oil solution in the quality analysis of heated vegetable oil. J. Mol. Liq. 238 (2017)136-144. doi:10.1016/j.molliq.2017.04.107.

[7].Senol Sirin, Turgay Kivakb, Performances of different eco-friendly nanofluid lubricants in the milling of Inconel X-750 superalloy, Tribology International 137 (2019) 180-192 https://doi.org/10.1016/j.triboint.2019.04.042

[8].Xue Han a, Steven J. Thrush et al ,Tribological characterization of $\mathrm{ZnO}$ nanofluids as fastener lubricants, Wear 468-469 (2021) 203592 https://doi.org/10.1016/j.wear.2020.203592

[9].YU, He-long, XU, Yi, SHI, Pei-jing, XU, Bin-shi, WANG, Xiao-li, LIU, Qian, Tribological properties and lubricating mechanisms of $\mathrm{Cu}$ nanoparticles in lubricant. Trans. Nonferrous Met. Soc. China. 18 (2008) 636-641. doi:10.1016/S10036326(08)60111-9.

[10]. M. Nabeel Rashin, J. Hemalatha, Viscosity studies on novel copper oxide-coconut oil nanofluid. Exp. Therm. Fluid Sci. 48(2013) 67-72. doi:10.1016/j.expthermflusci.2013.02.009.

[11]. Massimo Corcione, Empirical correlating equations for predicting the effective thermal conductivity and dynamic viscosity of nanofluids, Energy Conversion and Management 52 (2011) 789-793

[12]. P. Keblinski, S. R. Phillpot, S. U. S. Choi, J.A. Eastman, Mechanisms of heat flow in suspensions of nano-sized particles (nanofluids), International Journal of heat and mass transfer, 45 (2002) 855-863.

[13]. S.V. Sujith, Anand Kumar Solanki, Rahul S. Mulik, (2019) Experimental evaluation on rheological behavior of A12O3-pure coconut oil nanofluids, Journal of Molecular liquids, https://doi.org/10.1016/j.molliq.2019.110905

[14]. SinaNabati Shoghl, MasoudBahrami, Mohammad Jamialahmadi, The boiling performance of $\mathrm{ZnO}, \alpha-\mathrm{Al} 2 \mathrm{O} 3$ and MWCNTs/water nanofluids: An experimental study, Experimental Thermal and Fluid Science, 80 (2017), 27-39.

https://doi.org/10.1016/i.expthermflusci.2016.07.024

[15]. Ricardo Ayerza, Seed characteristics, oil content and fatty acid composition of 
Moringa (Moringa oleifera Lam.) seeds from three arid land locations in Ecuador, Industrial Crops \& Products 140 (2019) 111575.

https://doi.org/10.1016/i.indcrop.2019.111575

[16]. Ziquan Liu, Ruming Wang et at. Synthesis and characterization of $\mathrm{TiO}_{2}$ nanoparticles. (2014), 655-659. https://doi.org/10.14233/ajchem.2014.15462

[17]. Amin Asadi, Farzad Pourfattah, Heat transfer performance of two oil-based nanofluids containing $\mathrm{ZnO}$ and $\mathrm{MgO}$ nanoparticles; a comparative experimental investigation, Powder Technology 343 (2019) 296-308.

https://doi.org/10.1016/i.powtec.2018.11.023

[18]. Avneesh Kumar, D. Gannath Thakre, M.F. WaniI, Influence of load and speed on tribological performance of $\mathrm{Cu}$ nanofluids in EHL line contacts, (2020) https://doi.org/10.1016/j.matpr.2020.10.931

[19]. G. Żyła, J. Fal, Experimental studies on viscosity, thermal and electrical conductivity of aluminum nitride-ethylene glycol (AlN-EG) nanofluids. Thermochim. Acta. 637 (2016) 11-16. doi:10.1016/j.tca.2016.05.006.

[20]. S. Nabati Shoghl, J. Jamali, M. M. Keshavarz Moraveji, Electrical conductivity, viscosity, and density of different nanofluids: An experimental study. Exp. Therm. Fluid Sci. 74 (2016) 339-346. doi:10.1016/j.expthermflusci.2016.01.004.

[21]. I. M. Mahbubul, R. Saidur, M. A. Amalina, Latest developments on the viscosity of nanofluids. Int. J. Heat Mass Transf. 55 (2011) 874-885.

doi:10.1016/j.ijheatmasstransfer.2011.10.021.

[22]. Praveen K.Namburu, Devdatta P.Kulkarni, DebasmitaMisra, Debendra K. Das, Viscosity of copper oxide nanoparticles dispersed in ethylene glycol and water mixture, Experimental Thermal and Fluid Science, 32, (2007), 397-402. https://doi.org/10.1016/j.expthermflusci.2007.05.001

[23]. S. Rubalya Valantina, K. Arockia Jayalatha, D.R. Phebee Angeline , S. Uma , B. Ashvanth, 2018, Synthesis and characterisation of electro-rheological property of novel eco-friendly rice bran oil and nanofluid, Journal of Molecular Liquids 256 (2018) 256266. https://doi.org/10.1016/j.molliq.2018.01.183

[24]. SKS, LVV, RKS (2016) ZnO-propylene glycol-water nanofluids with improved properties for potential applications in renewable energy and thermal management. Colloids Surfaces A Physicochem. Eng. Asp. 506: 63-73. doi:10.1016/j.colsurfa.2016.06.007. 
Figures

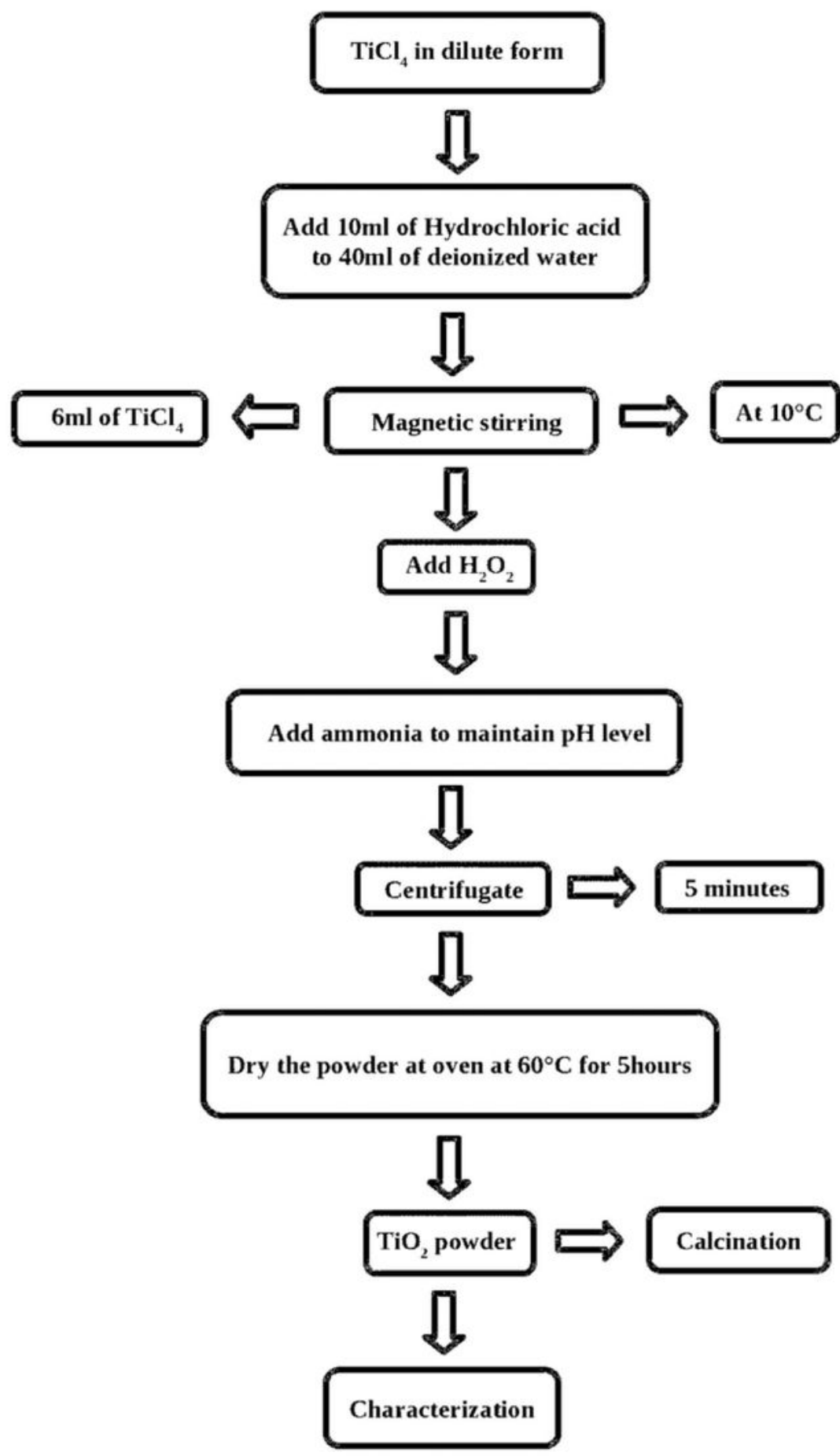

Figure 1

Preparation of TiO2: 


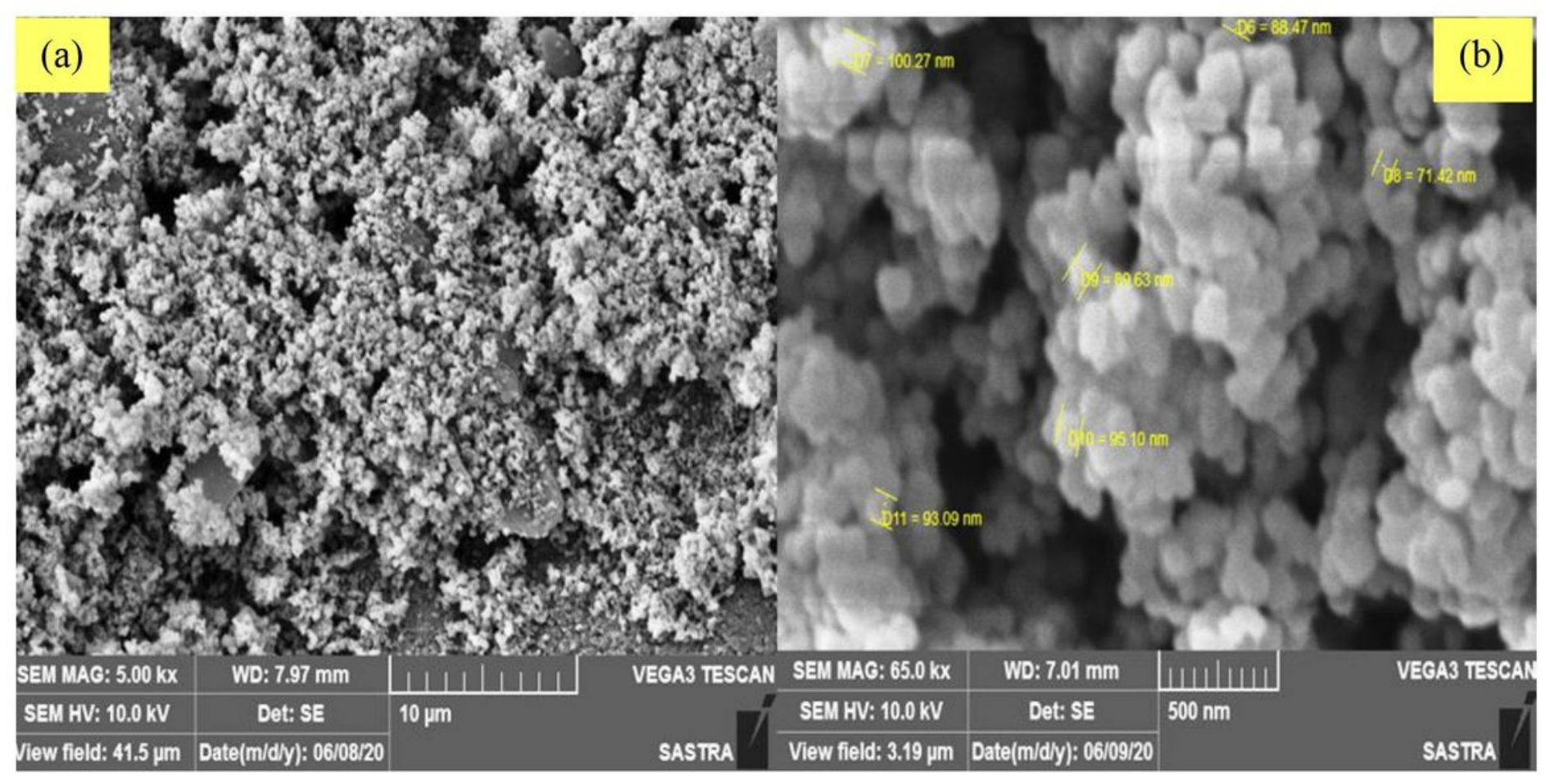

\section{Figure 2}

SEM image of TiO2: (a) Magnification with $10 \square \mathrm{m}$, and (b) Magnification with 500nm 


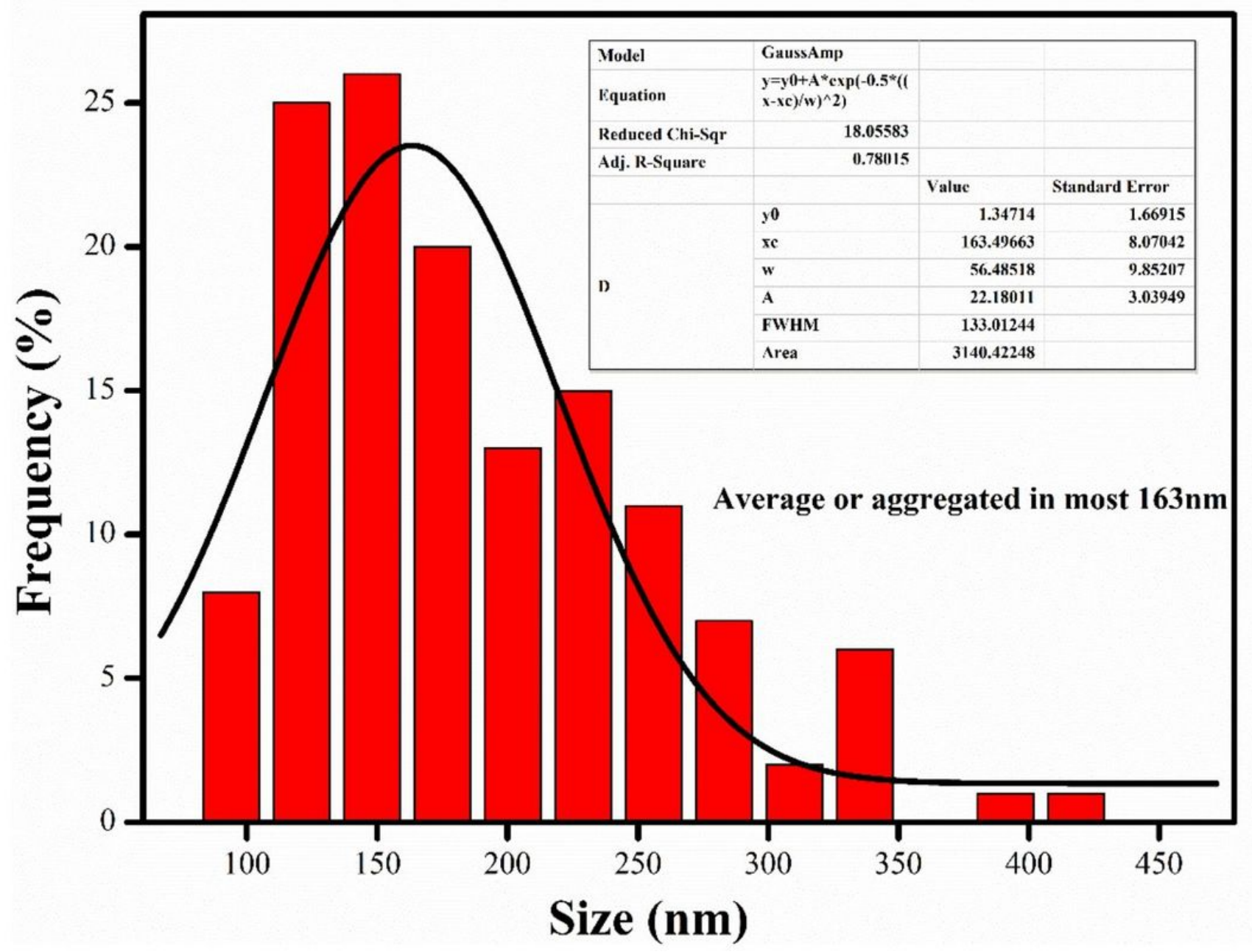

Figure 3

Characterisation of $\mathrm{TiO} 2$ of size $24 \mathrm{~nm}$ distributed in nanoparticles 


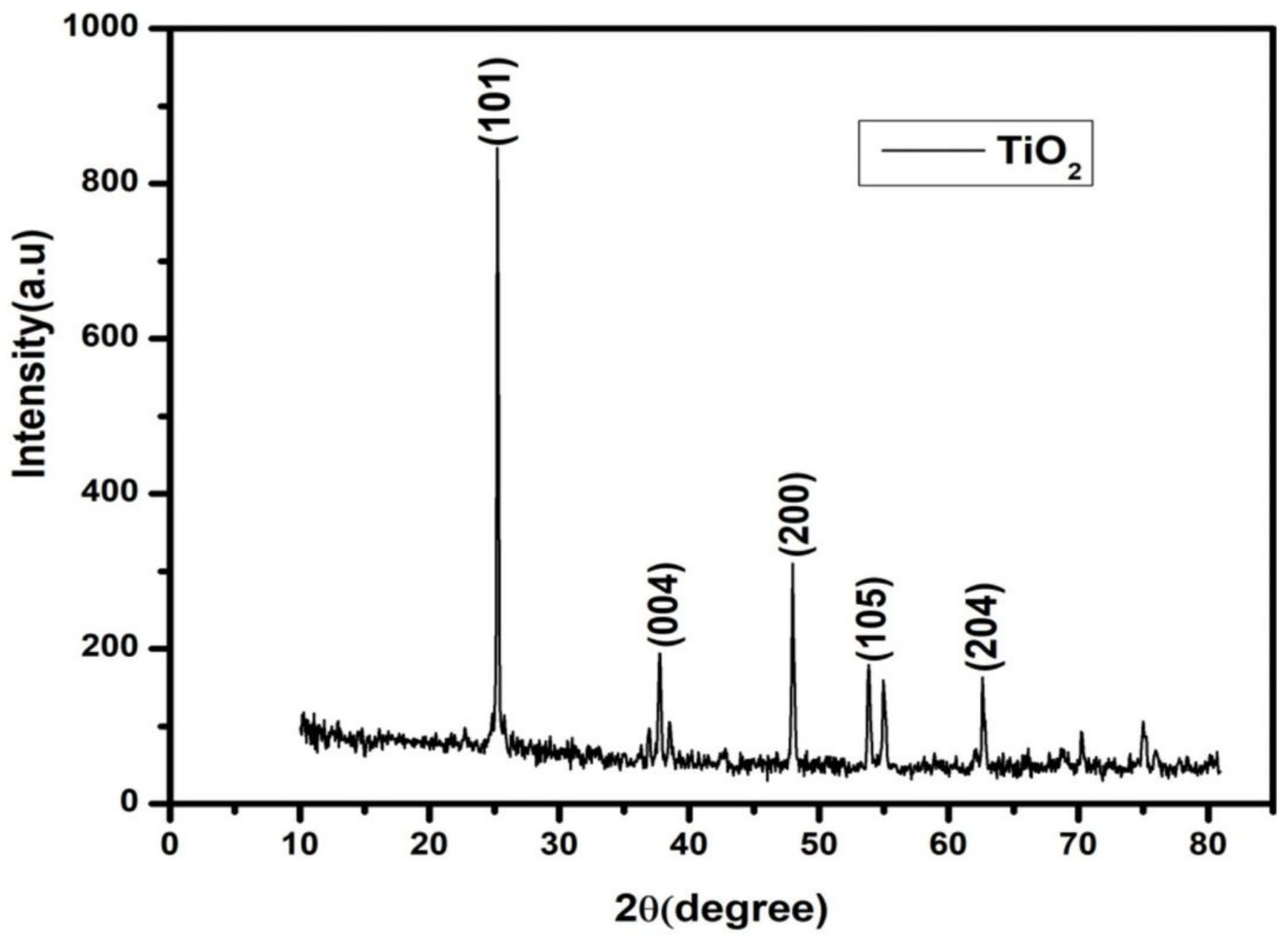

Figure 4

XRD of TiO2 nanopowder 


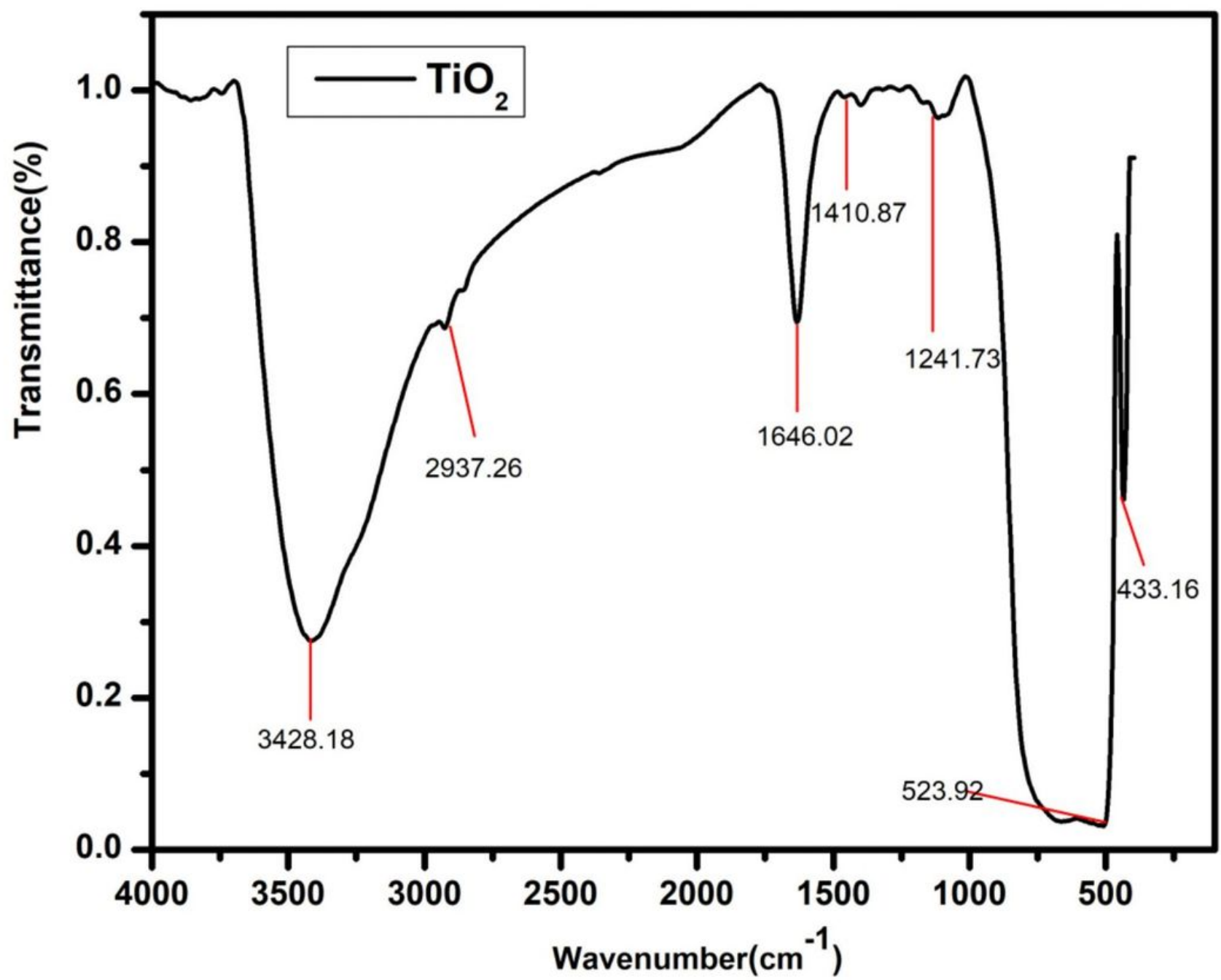

Figure 5

FTIR analysis of $\mathrm{TiO} 2$ 


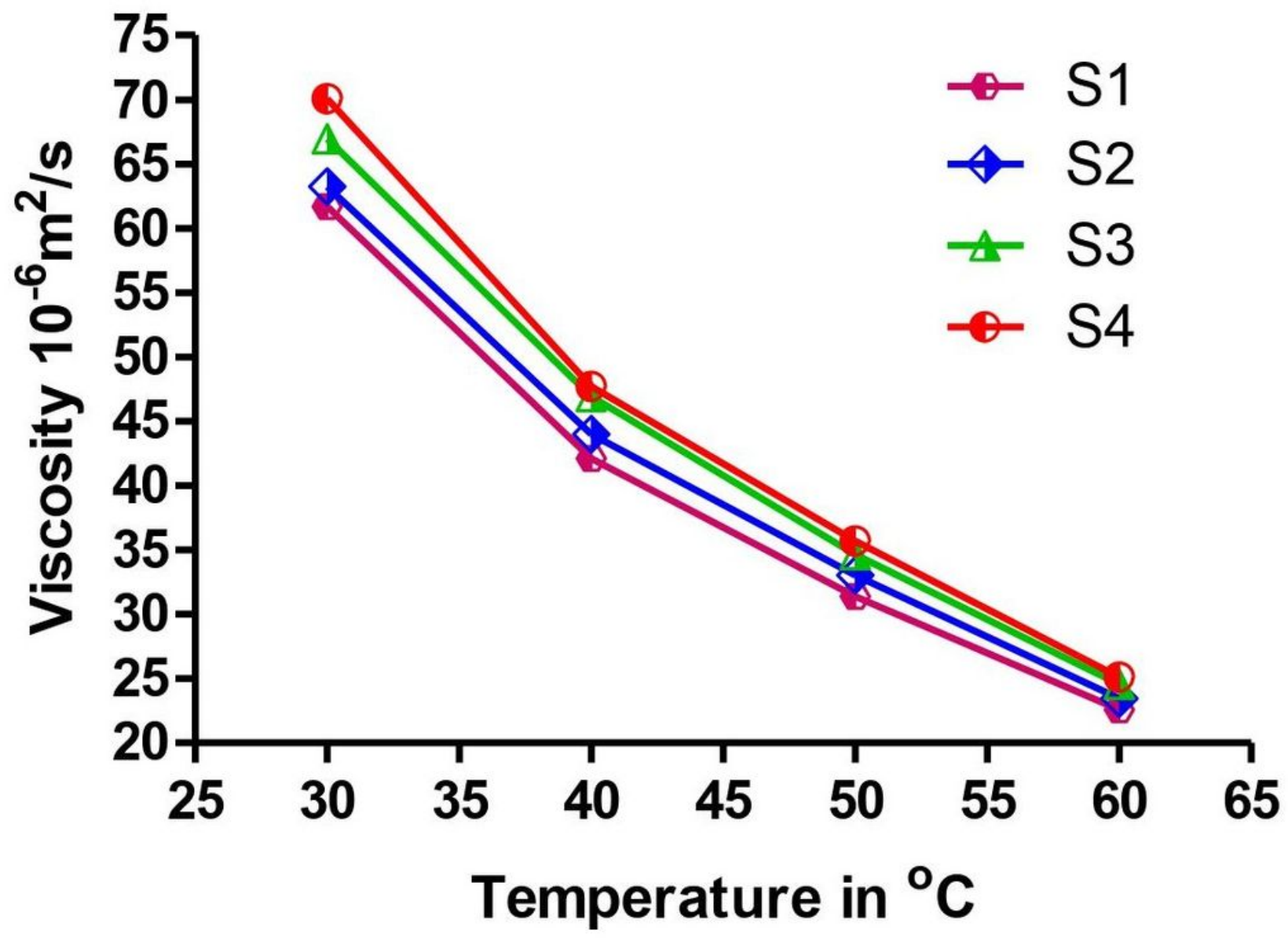

Figure 6

Variation of viscosity with temperature and volume fraction 


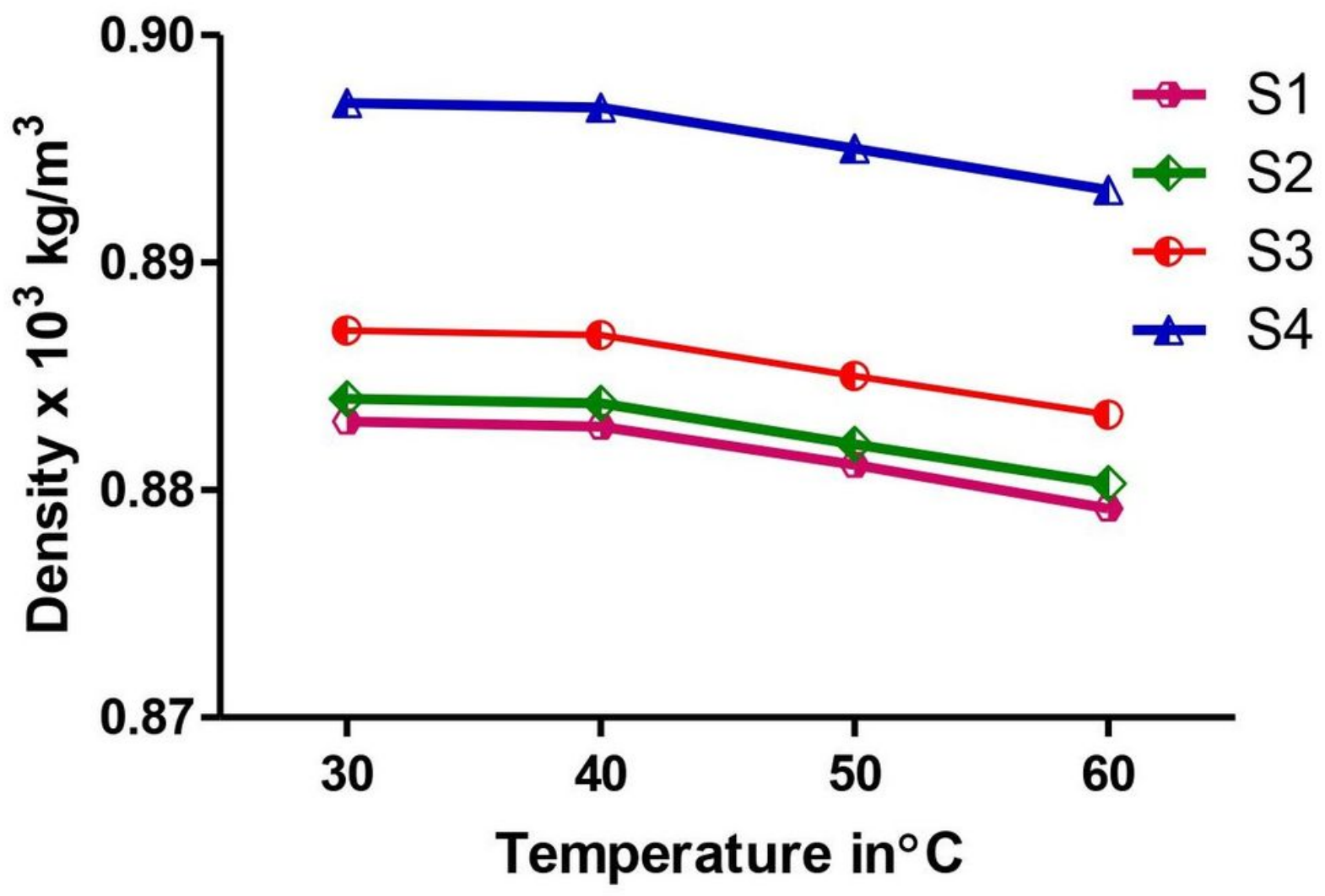

Figure 7

Variation of density with temperature and volume fraction

Supplementary Files

This is a list of supplementary files associated with this preprint. Click to download.

- Table12052021.docx 